\title{
Size matters: relationships between body size and body mass of common coastal, aquatic invertebrates in the Baltic Sea
}

\author{
Johan Eklöf Corresp.., ${ }^{1}$ ， Åsa Austin ${ }^{1}$ ， Ulf Bergström ${ }^{2}$ ， Serena Donadi ${ }^{1,3}$ ， Britas D H K Eriksson ${ }^{4}$, Joakim Hansen \\ 3 , Göran Sundblad ${ }^{5}$ \\ ${ }^{1}$ Department of Ecology, Environment and Plant sciences (DEEP), Stockholm University, Stockholm, Sweden \\ 2 Department of Aquatic Resources, Swedish University of Agricultural Sciences, Öregrund, Sweden \\ 3 Baltic Sea Centre, Stockholm University, Stockholm, Sweden \\ 4 Groningen Institute for Evolutionary Life-Sciences GELIFES, University of Groningen, Groningen, Netherlands \\ 5 Aquabiota Water Research, Stockholm, Sweden \\ Corresponding Author: Johan Eklöf \\ Email address: johan.eklof@su.se
}

Background. Organism biomass is one of the most important variables in ecological studies, making biomass estimations one of the most common laboratory tasks. Biomass of small macroinvertebrates is usually estimated as dry mass or ash-free dry mass (hereafter 'DM' vs. 'AFDM') per sample; a laborious and time consuming process, that often can be speeded up using easily measured and reliable proxy variables like body size or wet (fresh) mass. Another common way of estimating AFDM (one of the most accurate but also time-consuming estimates of biologically active tissue mass) is the use of AFDM/DM ratios as conversion factors. So far, however, these ratios typically ignore the possibility that the relative mass of biologically active vs. non-active support tissue (e.g. protective exoskeleton or shell) - and therefore, also AFDM/DM ratios - may change with body size, as previously shown for taxa like spiders, vertebrates and trees.

Methods. We collected aquatic, epibenthic macroinvertebrates (>1 mm) in 32 shallow bays along a 360 $\mathrm{km}$ stretch of the Swedish coast along the Baltic Sea; one of the largest brackish water bodies on Earth. We then estimated statistical relationships between the body size (length or height in mm), body dry mass and ash-free dry mass for 14 of the most common taxa; five gastropods, three bivalves, three crustaceans and three insect larvae. Finally, we statistically estimated the potential influence of body size on the AFDM/DM ratio per taxon.

Results. For most taxa, non-linear regression models describing the power relationship between body size and i) DM and ii) AFDM fit the data well (as indicated by low SE and high $\mathrm{R}^{2}$ ). Moreover, for more than half of the taxa studied (including the vast majority of the shelled molluscs), body size had a negative influence on organism AFDM/DM ratios.

Discussion. The good fit of the modelled power relationships suggest that the constants reported here can be used to more quickly estimate organism dry- and ash-free dry mass based on body size, thereby freeing up considerable work resources. However, the considerable differences in constants between taxa emphasize the need for taxon-specific relationships, and the potential dangers associated with ignoring body size. The negative influence of body size on the AFDM/DM ratio found in a majority of the molluscs could be caused by increasingly thicker shells with organism age, and/or spawning-induced loss of biologically active tissue in adults. Consequently, future studies utilizing AFDM/DM (and presumably also AFDM/wet mass) ratios should carefully assess the potential influence of body size to ensure more reliable estimates of organism body mass. 
1 Size matters: relationships between body size and body mass of common coastal, aquatic invertebrates in the Baltic Sea

3

\section{Short title: Body size and biomass estimations}

5

6 Eklöf JS ${ }^{1 *}$, Austin $\AA^{1}$, Bergström $\mathrm{U}^{2}$, Donadi $\mathrm{S}^{1,3}$, Eriksson $\mathrm{BK}^{4}$, Hansen $\mathrm{J}^{3}$, Sundblad $\mathrm{G}^{5}$

7

8 1: Department of Ecology, Environment and Plant Sciences. Stockholm University, Stockholm,

9 Sweden

10 2: Department of Aquatic Resources, Swedish University of Agricultural Sciences, Öregrund,

11 Sweden

12 3: Baltic Sea Centre, Stockholm University, Stockholm, Sweden

13 4: Groningen Institute for Evolutionary Life-Sciences GELIFES, University of Groningen,

14 Groningen, the Netherlands

15 5: Aquabiota Water Research, Stockholm, Sweden

16

$17 *$ : corresponding author. Email: johan.eklof@su.se

18

19 


\section{ABSTRACT (417 words)}

21 Background. Organism biomass is one of the most important variables in ecological studies,

22 making biomass estimations one of the most common laboratory tasks. Biomass of small

23 macroinvertebrates is usually estimated as dry mass or ash-free dry mass (hereafter 'DM' vs.

24 'AFDM') per sample; a laborious and time consuming process, that often can be speeded up using

25 easily measured and reliable proxy variables like body size or wet (fresh) mass. Another common

26 way of estimating AFDM (one of the most accurate but also time-consuming estimates of

27 biologically active tissue mass) is the use of AFDM/DM ratios as conversion factors. So far,

28 however, these ratios typically ignore the possibility that the relative mass of biologically active

vs. non-active support tissue (e.g. protective exoskeleton or shell) - and therefore, also AFDM/DM ratios - may change with body size, as previously shown for taxa like spiders, vertebrates and trees.

31 Methods. We collected aquatic, epibenthic macroinvertebrates $(>1 \mathrm{~mm})$ in 32 shallow bays along

32 a $360 \mathrm{~km}$ stretch of the Swedish coast along the Baltic Sea; one of the largest brackish water bodies on Earth. We then estimated statistical relationships between the body size (length or height in $\mathrm{mm}$ ), body dry mass and ash-free dry mass for 14 of the most common taxa; five gastropods, three bivalves, three crustaceans and three insect larvae. Finally, we statistically estimated the potential influence of body size on the AFDM/DM ratio per taxon.

37 Results. For most taxa, non-linear regression models describing the power relationship between 38 body size and i) DM and ii) AFDM fit the data well (as indicated by low SE and high $\mathrm{R}^{2}$ ). Moreover, for more than half of the taxa studied (including the vast majority of the shelled molluscs), body size had a negative influence on organism AFDM/DM ratios.

41 Discussion. The good fit of the modelled power relationships suggest that the constants reported

42 here can be used to more quickly estimate organism dry- and ash-free dry mass based on body 
43 size, thereby freeing up considerable work resources. However, the considerable differences in

44 constants between taxa emphasize the need for taxon-specific relationships, and the potential

45 dangers associated with ignoring body size. The negative influence of body size on the AFDM/DM

46 ratio found in a majority of the molluscs could be caused by increasingly thicker shells with

47 organism age, and/or spawning-induced loss of biologically active tissue in adults. Consequently,

48 future studies utilizing AFDM/DM (and presumably also AFDM/wet mass) ratios should carefully

49 assess the potential influence of body size to ensure more reliable estimates of organism body

50 mass.

\section{INTRODUCTION}

Organism biomass is inarguably one of the more important variables in ecology, playing a central role in studies ranging from ecophysiology and community and food web regulation, to wholeecosystem metabolism (e.g. Enquist \& Niklas, 2001; Gruner et al., 2008; Perez-Harguindeguy et al., 2013). As a consequence, to accurately estimate organism biomass constitutes one of the most common and important tasks in ecological studies (Rosillo Callé, 2008). part of animal density, diversity and biomass in many ecosystems; e.g. insects and arachnids in terrestrial ecosystems; epibenthic, aquatic crustaceans, echinoderms and molluscs in stands of aquatic vegetation; and infaunal (sediment-dwelling) worms, crustaceans and molluscs in marine sediments. Macrofauna biomass is typically reported as dry- or ash-free dry mass per unit area 
66 (e.g. g per $\mathrm{m}^{2}$ ), which requires observers to repeatedly identify, sort, dry and weigh individual or

67 pooled organisms; a time-consuming, expensive and tedious process. Many studies have shown

68 that more easily measured proxy variables scale predictably with dry mass and therefore can be

69 used to speed up biomass estimations; e.g. wet (fresh) mass (Brey, Rumohr \& Ankar, 1988;

70 Ricciardi \& Bourget, 1998; Brey et al., 2010) and body size, based on either exact length

71 measurement (Smock, 1980; Frithsen, Rudnick \& Doering, 1986; Sabo, Bastow \& Power, 2002)

72 or retention on sieves of certain mesh sizes (Widbom, 1984; Edgar, 1990; Casagranda \&

73 Boudouresque, 2002). While wet mass can be a very good proxy (see e.g. Ricciardi \& Bourget,

74 1998), we - as others before - argue that body size (e.g. length) holds several advantages, and

75 lacks several disadvantages associated with wet mass estimations. First, ecological theory

76 supported by empirical data suggest body mass scales predictably with length in the form of power

77 relations (Smock, 1980; Sabo, Bastow \& Power, 2002). Second, while freezing/thawing and

78 fixation in conservation liquids (e.g. EtOH or formalin) can affect both organism wet mass

79 (Howmiller, 1972; Mason, Lewis \& Weber, 1983; Leuven, Brock \& van Druten, 1985) and length

80 (Hjörleifsson \& Klein-MacPhee, 1992; Kapiris, Miliou \& Moraitou-Apostolopoulou, 1997), wet

81 mass estimations are also very sensitive to exactly how specimens are blotted, centrifuged (to

82 remove excess water), and exposed to air and light before and during weighing (Howmiller, 1972;

83 Mason, Lewis \& Weber, 1983; Leuven, Brock \& van Druten, 1985). As size estimations do not

84 require blotting, they are less sensitive to observer error, and also faster to perform. Third, body

85 size (e.g. length or height) estimations can more easily be automated, using e.g. image analysis

86 software (Paavo et al., 2008; Mallard, Le Bourlot \& Tully, 2013), to rapidly process multiple

87 individuals at a time.

88 In benthic ecology, ash-free dry mass (hereafter 'AFDM', in the older literature called 'ash- 
89 free dry weight' or simply 'AFDW') is often regarded as the most accurate predictor of macrofauna

90 biomass, as it only includes biologically active tissue. Since AFDM estimations require the

91 incineration of dried samples in a furnace at high temperature, adding considerable time and costs

92 to analyses, many studies have reported how AFDM scales with estimations of wet- and dry mass,

93 usually in the form of simple ratios as 'conversion factors' (e.g. AFDM/DM, in \%) (Rumohr, Brey

94 \& Ankar, 1987; Ricciardi \& Bourget, 1998). However, these ratios typically ignore the possibility

95 that the relative mass of biologically active vs. non-active support tissue (e.g. protective

96 exoskeleton or shell) - and therefore the AFDM/DM ratio - may change with macrofauna body

97 size, as previously shown for disparate taxa like spiders (Andersen, 1979), vertebrates (Miller \&

98 Birchard, 2005) and trees (Niklas, 1995). This issue is important not only for obtaining accurate

99 biomass conversions and estimations, but also for understanding how organismal investment in

100 one type of structure may limit or constrain investment in other structures across ontogenetic

101 development stages (Lease \& Wolf, 2010).

102 Here we estimate and report relationships between body size, dry mass and ash-free dry

103 mass for 14 of the most common aquatic, epibenthic invertebrate taxa found in shallow, vegetated

104 habitats of the central Baltic Sea; one of the largest brackish water bodies on Earth. For each taxon

105 we also assess whether the ash-free dry mass/dry mass ratio changes with body size. Our aim is to

106 provide simple yet reliable size-based relationships that can be used to rapidly estimate organism

107 body mass and, ultimately, biomass per sample.

108

109 METHODS

110 Study area

111 The Baltic Sea is a $415000 \mathrm{~km}^{2}$ large marginal sea situated in northern Europe $\left(53-66^{\circ} \mathrm{N} ; 10-30^{\circ}\right.$ 
112 E). A main feature is the presence of strong horizontal and vertical gradients in salinity,

113 temperature and oxygen, that also undergo considerable temporal (e.g. seasonal) fluctuations

114 (Voipio, 1981). The Baltic Sea is evolutionary very young (ca 6000 years), and the shallow coastal

115 areas have since the last glaciation been colonized by a mixture of marine, freshwater and brackish

116 organisms, including crustaceans, gastropods, bivalves, polychaetes, hirudineans, nemerteans and

117 insect larvae (Hansen, Wikström \& Kautsky, 2008). As many marine and freshwater organisms in

118 the Baltic Sea live near their physiological tolerance limits, they grow slower and smaller than in

119 their original environment; e.g. the blue mussel Mytilus edulis (Tedengren \& Kautsky, 1986). As

120 a consequence, their size ranges - but also size:mass relationships and, potentially, AFDM/DM

121 ratios - could differ from those reported for conspecifics in marine or freshwater areas (Rumohr,

122 Brey \& Ankar, 1987). An estimate of the effect of salinity on size:mass or DM:AFDM relationship

123 was beyond the scope of our study, but our results could be compared to relationships in marine

124 populations of the same taxa, if sampled and measured in the same way.

125

126 Field sampling

127 During summer (May-Aug) 2014 we collected aquatic invertebrate macrofauna (>1mm) in 32

128 shallow bays situated along a $360 \mathrm{~km}$ stretch of the central, Swedish Baltic Sea coastline (Fig. 1).

129 The salinity in the area is generally low (ca. 5-7 psu) but fluctuates strongly with freshwater runoff

130 and upwelling events. In each bay, a snorkeler sampled submerged aquatic vegetation and

131 epibenthic macrofauna in 3-8 randomly selected stations ( $>30 \mathrm{~m}$ apart), by gently placing a $20 \times 20$

$132 \mathrm{~cm}$ frame (with a $1 \mathrm{~mm}$-mesh bag attached) on the sea bed, and collecting all organisms (aquatic

133 vegetation and associated invertebrates) found above or on top of the sediment surface. The bag 
134 content was immediately transferred to a plastic bag, which was kept cold on ice until frozen $\left(-20^{\circ}\right.$

135 C), in most cases within 1-3 hours.

136

137 Body size estimations

138 Following thawing in room temperature, we identified intact invertebrate organisms to the highest

139 taxonomic resolution feasible using standard literature. For the 14 most common taxa we then

140 selected and measured the body size of 12-459 individuals per taxa (3220 individuals in total),

141 chosen to capture the full range of body sizes found across the 32 bays. The taxa included five

142 gastropods (Theodoxus fluviatilis, Hydrobia spp., Radix balthica, Potamopyrgus antipodarum,

143 Bithynia tentaculata), three bivalves (Mytilus edulis, Limecola (Macoma) balthica and Cardidae

144 spp. [numerically dominated by Parvicardium hauniense], three crustaceans (Amphibalanus

145 improvisus, Idotea spp., Gammarus spp.) and three insects (larval stages of Chironomidae spp.,

146 Agraylea spp. and Phryganeidae spp.) (see also Table 1). Body size (to the nearest $1 \mathrm{~mm}$ ) was

147 measured (based on standard procedures; Hayward \& Ryland, 1995) as; i) gastropod height along

148 the central shell axis, ii) bivalve length from anterior to posterior side, iii) total length of Gammarus

149 and Idotea spp. from tip of rostrum to last urosome, iv) body width for Amphibalanus improvisus,

150 and v) total length of insect larvae from end of head to last segment. A higher size accuracy is

151 definitely possible (e.g. to 0.1 or $0.01 \mathrm{~mm}$ using calipers or stereo lenses), but as most studies

152 utilizing this type of data (including ours) will depend on 1000s of length measurements, the

153 accuracy chosen was a realistic trade-off between time and precision.

154

\section{Estimations of dry- and ash-free dry mass}


156 Following size estimations, the measured individuals were transferred to pre-dried and -weighed

157 (nearest $0.0001 \mathrm{~g}$ ) porcelain crucibles. For most size classes (except for very large and rare

158 individuals), multiple individuals were typically pooled into the same crucible. This step

159 underestimates actual variability in body mass between individuals, but was necessary as the low

160 individual body masses (particularly AFDM) were near or below the reliable detection limit of the

161 scale. We included multiple estimations of the same sizes, so that the number of biomass

162 estimations (N) ranged from 10 to 42 per taxa. Samples were then dried at $60{ }^{\circ} \mathrm{C}$ for $>48 \mathrm{~h}$ (until

163 constant mass), and cooled to room temperature in a desiccator before weighing. To estimate ash-

164 free dry mass, the crucibles were then transferred to a muffle furnace, incinerated $\left(550{ }^{\circ} \mathrm{C}\right.$ for 3

165 hours), cooled and weighed again. Ash-free dry mass was calculated as dry mass minus ash mass.

166

167 Statistical analyses

168 We estimated taxon-specific body size:body mass relationship using non-linear regression in the

169 form of the power equation:

$$
\text { body mass }=\alpha \times \operatorname{size}^{\beta}
$$

171 where body mass is the individual mass (mg DM or AFDM), size is the body size (length/height,

172 in $\mathrm{mm}), \alpha$ is a normalization constant, and $\beta$ is the scaling constant. Body mass typically scales

173 with size in a power relationship, and initial data exploration showed that power equations

174 provided a superior fit compared to linear, log or exponential relationships. As regression

175 coefficients $\left(\mathrm{R}^{2}\right)$ are an inadequate measure of fit for non-linear regression models (Spiess \&

176 Neumeyer, 2010), we report SE for $\alpha$ and $\beta$. However, for the sake of simplicity we also

177 estimated the linear log-log relationship between body size and biomass, and report the $\mathrm{R}^{2}$ for

178 those models (see e.g. Lease \& Wolf, 2010). 
181 1998). We then used linear regression to test whether body size (in mm) affected the AFDM/DM

182 ratio. Prior to analyses we checked assumptions of normality (by plotting predicted vs. observed

183 quantiles) and homoscedasticity (by plotting predicted vs. observed residuals). All analyses were

184 conducted in $\mathrm{R}$ v. 3.2.3 (R Core Team, 2016).

\section{RESULTS}

Relationships between body size and individual biomass

188 The relationships between body size $(\mathrm{mm})$, individual dry mass $(\mathrm{mg} \mathrm{DM})$ and ash-free dry mass

189 (mg AFDM) for all 14 taxa are displayed in Figure 2a-h, and the parameters (and their fit) are

190 presented in Table 1. For most of the taxa, body size was a very good predictor of individual DM,

191 as demonstrated by low SE and $\mathrm{R}^{2}$ near 1 . The model fits were slightly poorer for the three insect

192 taxa $\left(\mathrm{R}^{2}=0.60-0.82\right)$ and the gastropod Bithynia tentaculata $\left(\mathrm{R}^{2}=0.85\right)$ than for the other ten

193 taxa. For a majority (12 out of 14$)$ of the taxa, the scaling constants $(\beta)$ were well above $2(2.110$ -

194 3.590). The exceptions were the small gastropod Potamopyrgus antipodarum and chironomid

195 larvae, which had constants closer to 1 ( $\beta=1.368$ and 1.383 , respectively).

196 Body size was also a very good predictor of AFDM, even though model fits (based on SE

197 and $\mathrm{R}^{2}$ ) were slightly poorer than for DM (Table 1). Just as for DM relationships, the model fits

198 (based on $\mathrm{SE}$ and $\mathrm{R}^{2}$ ) were best for gastropods, molluscs and crustaceans. The scaling constants

199 ( $\beta$ ) were for most taxa quite similar to those reported for the DM relationships, with the exception

200 of a higher constant for P. antipodarum $(\beta=2.447)$ and a lower constant for Bithynia tentaculata

$201 \quad(\beta=1.360)$. 
Influence of organism body size on AFDM/DM ratios

204 The AFDM/DM ratios (mean $\% \pm$ SE) per taxa are also presented in Table 1. As expected, there 205 were consistent differences between the four major taxonomic groups studied, with low AFDM content in bivalves and gastropods (12-27\%), who's calcium carbonate shell makes up the major 207 part of whole-body biomass, to higher AFDM content in chitin-shelled crustaceans (ca 60\%), and the highest content in insect larvae (86-92\%).

Results of simple linear regression showed that for more than half ( 8 out of 14) of the taxa surveyed, body size clearly affected the AFDM/DM ratio (Table 1, Fig. 2i-1). For four out of five gastropods, two out of three bivalves, as well as the sessile, calcite-shelled crustacean Amphibalanus improvisus, the AFDM/DM ratio decreased linearly with body size. For the small gastropod Potamopyrgus antipodarum body size instead had a positive influence on AFDM/DM.

214 However, the P. antipodarum size range was very narrow $(2-4 \mathrm{~mm})$ and the intercept was not

215 different from 0 (Table 1), suggesting a relatively poor model fit. Moreover, there was no size 216 effect found in the blue mussel Mytilus edulis (Table 1). Finally, in contrast to the size effects 217 found for most of the hard-shelled molluscs, there was no influence of body size on AFDM/DM 218 in any of the chitin-shelled crustaceans or insect larvae (Table 1, Fig 2i-1).

\section{DISCUSSION}

222 Estimating organism biomass is one of the most common, important but also resource-consuming 223 tasks in ecological work, particularly when it comes to small-bodied, highly abundant and diverse 224 macroscopic invertebrates. Many previous studies have shown that more easily measured variables 
225 like invertebrate wet (fresh) mass (e.g. Ricciardi \& Bourget, 1998) or body size (e.g. Smock, 1980)

226 can be used as proxies to reliably predict both the dry- and ash-free dry body mass, thereby

227 simplifying and speeding up biomass estimations. Here, we first complement this literature by

228 reporting how body mass scales with body size for 14 of the most common epibenthic invertebrate

229 taxa found in shallow coastal areas of the Baltic Sea. Moreover, we demonstrate that for a majority

230 of the studied molluscs, the ratio between organism dry- and ash-free dry mass - an often-used

231 conversion factor (e.g. Rumohr, Brey \& Ankar, 1987; Ricciardi \& Bourget, 1998) - decreases

232 predictably with body size. Thus, our results can be used to quickly estimate the biologically active

233 biomass of individual organisms based on their size, and when combined with density data,

234 accurately estimate biomass per unit area.

235

236 Body size as a proxy for dry-and ash-free dry mass

237 For a majority of the studied taxa, body size was a good predictor of both dry mass and ash-free 238 dry mass. The model fits were slightly poorer for ash-free dry mass (AFDM); most likely a 239 consequence of the fact that even though multiple individuals of the same size were pooled, the 240 low individual AFDM of many organisms (in the vicinity of $1 \mathrm{mg}$ ) challenged the accuracy of the 241 scale. Comparisons between the 14 taxa studied (Table 1) show that particularly within the 242 gastropods and crustaceans, the scaling $(\beta)$ constants differ quite substantially between taxa (see

243 the different slopes in Fig. 2 and $\beta$ coefficients in Table 1). These differences emphasize the need

244 for taxon-specific relationships to accurately predict biomass, and the potential dangers in either

245 ignoring body size or substituting relationships between taxa. Consequently, our power equations

246 (Table 1) can be used in a simple yet reliable way to estimate organism dry- or ash-free dry mass

247 based on standard body size measurements. Future studies should ideally also assess how these 
248 relationships vary in time and space (e.g. over seasons), for even more accurate biomass

249 estimations. Size-based biomass estimations are likely to speed up laboratory work considerably;

250 for example, Casagranda and Boudouresque (2002) showed that sieve-based size estimations

251 speeded up estimations of body biomass of the gastropod Hydrobia ventricosa by 20-30 times.

252 Consequently, our size-based estimations of invertebrate biomass are likely to free up considerable

253 work resources (time, man-power, money) that can be used to e.g. collect and process more 254 samples.

256 The influence of body size on AFDM/DM ratios

257 For most of the taxa with a calcium-carbonate (molluscs) or calcite shell (the barnacle 258 Amphibalanus improvisus), we found a significant negative influence of body size on the $259 \mathrm{AFDM} / \mathrm{DM}$ ratio; a commonly reported and often-used conversion factor in macrofauna studies 260 (e.g. Rumohr, Brey \& Ankar, 1987; Ricciardi \& Bourget, 1998). In other words, the proportional 261 mass of biologically active vs. non-active tissue (shell, hard mouth parts, etc.) decreased with body 262 size. There are at least two possible and complementary explanations for this relationship. First, 263 while the rate of growth in length of mollusc shells typically decreases with age, new shell layers 264 are consistently added on a yearly basis (Negus, 1966). This results in increasingly thicker, and 265 therefore disproportionally heavier, shells with mussel length, and a higher shell:tissue mass ratio. 266 Second, our sampling was conducted during summer; a season when a majority of adult molluscs

267 (here represented by the larger individuals per taxa) most likely had spawned and temporarily lost 268 a considerable proportion of their biologically active tissue (Kautsky, 1982). The slopes of the 269 significant regressions (Table 1 , median $=-1.26$ ) suggest that failing to incorporate the potential 270 influence of body size can strongly reduce the accuracy of AFDM estimations based on dry mass 
271 (and presumably also wet mass), particularly if there is considerable variability in body size in the

272 samples. The somewhat surprising lack of size influence in the common blue mussel Mytilus edulis

273 was not investigated in detail, but could be caused by i) the lack of small shell-crushing mussel

274 predators in the area (e.g. crabs), who otherwise are known to trigger thicker mussel shells

275 (Freeman, 2007), and/or ii) the relatively low salinity, which causes the small, osmotically stressed

276 M. edulis to invest considerably more energy into osmosis and soft tissue production, than in

277 thicker shells (Kautsky, Johannesson \& Tedengren, 1990).

278 In contrast to the results for molluscs, there was no size effect on AFDM/DM ratios for the

279 chitin-shelled insects and crustaceans. These results fit well with those reported in previous studies,

280 for example of terrestrial insects, for which exoskeletal chitin scales isometrically (1:1) with body

281 size (Lease \& Wolf, 2010). In summary, our results suggest that body size can play an important

282 but hitherto underestimated role when estimating organism AFDM based on dry (and possibly, 283 wet) mass, particularly for shelled molluscs.

285 Conclusions

286 Using samples of epibenthic macroinvertebrates collected in 32 shallow bays along a $360 \mathrm{~km}$

287 stretch of the Swedish Baltic Sea coast, we show that for 14 of the most common macrofauna taxa, 288 organism body size scales predictably with individual dry mass and ash-free dry mass in the form 289 of power relations. The good model fits suggest the taxon-specific equations reported here can be 290 used to predict individual biomass based on organism size, thereby speeding up estimations of 291 macrofauna biomass. Moreover, for the vast majority of the molluscs studied, we find a negative 292 relationship between body size and AFDM/DM ratio; a commonly used conversion factor in 293 macrofauna studies. Consequently, future studies utilizing AFDM/DM ratios should carefully 
294 assess the potential influence of body size and spatial-temporal variability, to ensure reliable 295 biomass estimations.

296

297 Acknowledgements

298 We acknowledge the field and/or laboratory assistance of (in alphabetic order) T. Amgren, E.

299 Anderberg, F. Ek, P. Jacobsson, G. Johansson, C. Jönander, L. Näslund, O. Pettersson, M. van

300 Regteren, S. Skoglund, E. Svartgren, V. Thunell, C. Åkerlund and M. Åkerman. We thank the

301 water right owners around each study bay for facilitating the field sampling. This study is a

302 product of project Plant-Fish (www.plantfish.se).

303

304 References $($ count $=\mathbf{3 6})$

305 Andersen SO. 1979. Biochemistry of Insect Cuticle. Annual Review of Entomology 24:29-59. DOI:

306 10.1146/annurev.en.24.010179.000333

307 Brey T, Muller-Wiegmann C, Zittier ZMC, and Hagen W. 2010. Body composition in aquatic 308 organisms - A global data bank of relationships between mass, elemental composition and energy content. Journal of Sea Research 64:334-340. DOI: 10.1016/j.seares.2010.05.002

Brey T, Rumohr H, and Ankar S. 1988. Energy content of macrobenthic invertebrates: general conversion factors from weight to energy. Journal of Experimental Marine Biology and Ecology 117:271-278. DOI: 10.1016/0022-0981(88)90062-7

313 Casagranda C, and Boudouresque CF. 2002. A sieving method for rapid determination of sizefrequency distribution of small gastropods. Example of the mud snail Hydrobia ventrosa. Hydrobiologia 485:143-152. DOI: 10.1023/A:1021371308753 
316 Edgar GJ. 1990. The use of the size structure of benthic macrofaunal communities to estimate

317 faunal biomass and secondary production. Journal of Experimental Marine Biology and

318 Ecology 137:195-214. DOI: 10.1016/0022-0981(90)90185-F

319 Enquist BJ, and Niklas KJ. 2001. Invariant scaling relations across tree-dominated communities. Nature 410:655-660. DOI: 10.1038/35070500

321 Freeman AS. 2007. Specificity of induced defenses in Mytilus edulis and asymmetrical predator 322 deterrence. Marine Ecology Progress Series 334. DOI: 10.3354/meps334145

323 Frithsen JB, Rudnick DT, and Doering PH. 1986. The determination of fresh organic carbon weight from formaldehyde preserved macrofaunal samples. Hydrobiologia 133:203-208. DOI: $10.1007 / \mathrm{BF} 00005591$

326

327

Gruner DS, Smith JE, Seabloom EW, Sandin SA, Ngai JT, Hillebrand H, Harpole WS, Elser JJ, Cleland EE, Bracken MES, Borer ET, and Bolker BM. 2008. A cross-system synthesis of consumer and nutrient resource control on producer biomass. Ecology Letters 11:740-755. DOI: 10.1111/j.1461-0248.2008.01192.x

Hansen JP, Wikström SA, and Kautsky L. 2008. Effects of water exchange and vegetation on the macroinvertebrate fauna composition of shallow land-uplift bays in the Baltic Sea. Estuarine, Coastal and Shelf Science 77:535-547. DOI: 10.1016/j.ecss.2007.10.013

Hayward PJ, and Ryland JS. 1995. Handbook of the Marine Fauna of North-West Europe. New York, USA: Oxford University Press. p 800.

Hjörleifsson E, and Klein-MacPhee G. 1992. Estimation of live standard length of winter flounder Pleuronectes americanus larvae from formalin-preserved, ethanol-preserved and frozen specimens. Marine Ecology Progress Series 82:13-19. DOI: 10.3354/meps082013 
338 Howmiller RP. 1972. Effects of Preservatives on Weights of Some Common Macrobenthic

339 Invertebrates. Transactions of the American Fisheries Society 101:743-746. DOI: 10.1577/1548-8659(1972)101<743:EOPOWO>2.0.CO;2

341 Kapiris K, Miliou H, and Moraitou-Apostolopoulou M. 1997. Effects of formaldehyde preservation on biometrical characters, biomass and biochemical composition of Acartia

Kautsky N. 1982. Quantitative studies on gonad cycle, fecundity, reproductive output and recruitment in a baltic Mytilus edulis population. Marine Biology 68:143-160. DOI:

Kautsky N, Johannesson K, and Tedengren M. 1990. Genotypic and phenotypic differences between Baltic and North Sea populations of Mytilus edulis evaluated through reciprocal transplantations. I. Growth and morphology. Marine Ecology Progress Series 59:203-210.

Lease HM, and Wolf BO. 2010. Exoskeletal chitin scales isometrically with body size in terrestrial DOI: $10.3354 /$ meps059203 insects. Journal of Morphology 271:759-768. DOI: 10.1002/jmor.10835

Leuven RSEW, Brock TCM, and van Druten HAM. 1985. Effects of preservation on dry- and ashfree dry weight biomass of some common aquatic macro-invertebrates. Hydrobiologia 127:151-159. DOI: 10.1007/BF00004193

Mallard F, Le Bourlot V, and Tully T. 2013. An automated image analysis system to measure and count organisms in laboratory microcosms. Plos ONE 8:e64387. DOI: 10.1371/journal.pone.0064387 
360 Mason WT, Lewis PA, and Weber CI. 1983. An evaluation of benthic macroinvertebrate biomass

361 methodology. Environmental Monitoring and Assessment 3:29-44. DOI:

362 10.1007/BF00394030

363 Miller K, and Birchard GF. 2005. Influence of Body Size on Shell Mass in the Ornate Box Turtle,

364 Terrapene ornata. Journal of Herpetology 39:158-161. DOI: 10.1670/00221511(2005)039[0158:IOBSOS]2.0.CO;2

Negus C. 1966. A Quantitative Study of Growth and Production of Unionid Mussels in the River Thames at Reading. Journal of Animal Ecology 35:513-532. DOI: 10.2307/2489

Niklas KJ. 1995. Size-dependent allometry of tree height, diameter and truck-taper. Annals of Botany. p 217-227. DOI: 10.1006/anbo.1995.1015

Paavo B, Ziegelmeyer A, Lavric E, and Probert PK. 2008. Morphometric correlations and body mass regressions for Armandia maculata, Aglaophamus macroura (Polychaeta), and Zethalia zelandica (Gastropoda). New Zealand Journal of Marine and Freshwater Research 42:85-91. DOI: 10.1080/00288330809509938

Perez-Harguindeguy N, Diaz S, Garnier E, Lavorel S, Poorter H, Jaureguiberry P, Bret-Harte MS, Cornwell WK, Craine JM, Gurvich DE, Urcelay C, Veneklaas EJ, Reich PB, Poorter L, worldwide. Australian Journal of Botany 61:167-234. DOI: 10.1071/bt12225 Statistical Computing. Vienna Austria. 
383 Ricciardi A, and Bourget E. 1998. Weight-to-weight conversion factors for marine benthic

384

385

386

387

388

389

390

391

392

393

394

395

396

397

398

399

400

401

402

403

404

405

macroinvertebrates. Marine Ecology-Progress Series 163:245-251. DOI: $10.3354 /$ meps 171245

Rosillo Callé F. 2008. The biomass assessment handbook: bioenergy for a sustainable environment. Routledge.

Rumohr H, Brey T, and Ankar S. 1987. A compilation of biometric conversion factors for benthic invertebrates of the Baltic Sea. The Baltic Marine Biologists 9:1-56. DOI: $10.3354 / \operatorname{meps} 171245$

Sabo JL, Bastow JL, and Power ME. 2002. Length-Mass relationships for adult aquatic and terrestrial invertebrates in a California watershed. Journal of the North American Benthological Society 21:336-343. DOI: 10.2307/1468420

Smock LA. 1980. Relationships between body size and biomass of aquatic insects. Freshwater Biology 10:375-383. DOI: 10.1111/j.1365-2427.1980.tb01211.x

Spiess A-N, and Neumeyer N. 2010. An evaluation of R2 as an inadequate measure for nonlinear models in pharmacological and biochemical research: a Monte Carlo approach. $B M C$ pharmacology 10:6. DOI: 10.1186/1471-2210-10-6

Tedengren M, and Kautsky N. 1986. Comparative study of the physiology and its probable effect on size in Blue Mussels (Mytilus Edulis L.) from the North Sea and the Northern Baltic Proper. Ophelia 25:147-155. DOI: 10.1080/00785326.1986.10429746

Voipio A. 1981. The Baltic Sea. Elsevier Science.

Widbom B. 1984. Determination of average individual dry weights and ash-free dry weights in different sieve fractions of marine meiofauna. Marine Biology 84:101-108. DOI: 10.1007/BF00394532 
407 Table 1. Results of regression analyses estimating i) the non-linear power relationship between body size and dry mass (DM) and ii)

408 ash-free dry mass (AFDM), iii) the mean \pm 1SE AFDM/DM ratio (in \%), and iv) the linear relationship between body size and

$409 \mathrm{AFDM} / \mathrm{DM}$ ratio (in \%), for 14 macroinvertebrate taxa in shallow coastal areas of the Baltic Sea. Letters within parentheses after taxa

410 names denote classes, where G: Gastropoda, B: Bivalvia, C: Crustacea, and I: Insecta (larvae). $\alpha$ and $\beta$ : normalization and scaling

411 constant for power equations, respectively. ns: $p>0.05, *$ : $<<0.05, * *: p<0.01, * * *: p<0.001$. Values in bold mark those significant (at $\alpha$

$412=0.05)$. Note: $\mathrm{R}^{2}$ were derived from linear log-log models.

413

\begin{tabular}{|c|c|c|c|c|c|c|c|c|c|c|c|}
\hline \multirow[b]{2}{*}{ Taxon } & \multirow[b]{2}{*}{$\mathbf{N}$} & \multicolumn{3}{|c|}{ Body size vs. DM } & \multicolumn{3}{|c|}{ Body size vs. AFDM } & \multirow{2}{*}{$\begin{array}{c}\text { AFDM/DM } \\
\text { Mean } \% \pm 1 S E\end{array}$} & \multicolumn{3}{|c|}{ Body size vs. AFDM/DM } \\
\hline & & $\alpha \pm \mathrm{SE}$ & $\beta \pm \mathrm{SE}$ & $\mathbf{R}^{2}$ & $\alpha \pm \mathrm{SE}$ & $\beta \pm \mathrm{SE}$ & $\mathbf{R}^{2}$ & & Intercept $\pm \mathrm{SE}$ & slope \pm SE & $\mathbf{R}^{2}$ \\
\hline Bithynia tentaculata $\mathrm{L} .(\mathrm{G})$ & 25 & $0.598 \pm 0.484^{\mathrm{ns}}$ & $2.117 \pm 0.351 * * *$ & 0.847 & $0.479 \pm 0.511^{\mathrm{ns}}$ & $1.36 \pm 0.472 * *$ & 0.668 & $19.133 \pm 2.207$ & $33.162 \pm 3.878 * * *$ & $-1.91 \pm 0.452^{*}$ & 0.424 \\
\hline Hydrobia spp. (G) & 24 & $0.239 \pm 0.041 * * *$ & $2.134 \pm 0.095 * * *$ & 0.952 & $0.079 \pm 0.029 *$ & $1.441 \pm 0.22 * * *$ & 0.758 & $13.737 \pm 1.155$ & $19.791 \pm 2.855 * * *$ & $-0.633 \pm 0.715 *$ & 0.155 \\
\hline $\begin{array}{l}\text { Potamopyrgus } \\
\text { antipodarum Gray (G) }\end{array}$ & 17 & $0.479 \pm 0.511^{\mathrm{ns}}$ & $1.360 \pm(0.472 * *$ & 0.919 & $0.021 \pm 0.012^{\mathrm{ns}}$ & $2.447 \pm 0.395 * * *$ & 0.898 & $16.051 \pm 1.399$ & $6.063 \pm 4.616^{\mathrm{ns}}$ & $2.653 \pm 1.180^{*}$ & 0.202 \\
\hline Radix balthica L. (G) & 20 & $0.137 \pm 0.035^{* *}$ & $2.355 \pm 0.115 * * *$ & 0.956 & $0.046 \pm 0.018 *$ & $2.119 \pm 0.177 * * *$ & 0.906 & $27.087 \pm 2.233$ & $35.338 \pm 3.558 * * *$ & $-1.794 \pm 0.650$ * & 0.258 \\
\hline Theodoxus fluviatilis L. (G) & 29 & $0.221 \pm 0.065^{* *}$ & $2.683 \pm 0.148 * * *$ & 0.9492 & $0.015 \pm 0.006 *$ & $2.915 \pm 0.194 * * *$ & 0.912 & $13.044 \pm 1.083$ & $18.52 \pm 2.396 * * *$ & $-0.242 \pm 0.494 *$ & 0.159 \\
\hline Cardidae spp. (B) & 33 & $0.134 \pm 0.094^{\mathrm{ns}}$ & $2.848 \pm 0.347 * * *$ & 0.924 & $0.014 \pm 0.013^{\mathrm{ns}}$ & $2.806 \pm 0.486 * * *$ & 0.879 & $12.358 \pm 0.852$ & $18.075 \pm 1.468^{* * *}$ & $-0.429 \pm 0.325 *$ & 0.364 \\
\hline Limecola balthica L. (B) & 18 & $0.069 \pm 0.024 *$ & $2.820 \pm 0.134 * * *$ & 0.991 & $0.001 \pm 0.002^{\mathrm{ns}}$ & $3.479 \pm 0.673 * * *$ & 0.92 & $12.717 \pm 1.934$ & $21.429 \pm 2.98 * * *$ & $-0.264 \pm 0.372 *$ & 0.383 \\
\hline Mytilus edulis L. (B) & 24 & $0.030 \pm 0.015^{*}$ & $2.933 \pm 0.153 * * *$ & 0.991 & $0.006 \pm 0.003 *$ & $2.844 \pm 0.147 * * *$ & 0.978 & $14.189 \pm 0.504$ & $13.162 \pm 1.044 * * *$ & $0.078 \pm 0.069^{\mathrm{ns}}$ & 0.011 \\
\hline $\begin{array}{l}\text { Amphibalanus improvisus } \\
\text { Darwin }(\mathrm{C})\end{array}$ & 13 & $0.314 \pm 0.205^{\mathrm{ns}}$ & $2.515 \pm 0.289 * * *$ & 0.976 & $0.036 \pm 0.022^{\mathrm{ns}}$ & $2.289 \pm 0.276 * * *$ & 0.961 & $8.939 \pm 0.550$ & $11.044 \pm 1.064 * * *$ & $-0.397 \pm 0.179 *$ & 0.246 \\
\hline Gammarus spp. (C) & 37 & $0.047 \pm 0.032^{\mathrm{ns}}$ & $2.111 \pm 0.265 * * *$ & 0.926 & $0.033 \pm 0.028^{\mathrm{ns}}$ & $2.05 \pm 0.32 * * *$ & 0.863 & $58.966 \pm 1.519$ & $63.062 \pm 2.616 * * * *$ & $-0.389 \pm 0.307^{\mathrm{ns}}$ & 0.017 \\
\hline Idothea spp. (C) & 42 & $0.001 \pm 0.001 \mathrm{~ns}$ & $3.592 \pm 0.200 * * *$ & 0.949 & $0.001 \pm 0.001^{\mathrm{ns}}$ & $3.850 \pm 0.249 * * *$ & 0.919 & $61.505 \pm 1.659$ & $66.183 \pm 3.457 * * *$ & $-0.550 \pm 0.358^{\mathrm{ns}}$ & 0.032 \\
\hline Agraylea spp. (I) & 13 & $0.001 \pm 0.002^{\text {ns }}$ & $3.410 \pm 0.721 * *$ & 0.820 & $0.001 \pm 0.002^{\mathrm{ns}}$ & $3.432 \pm 0.769 * * *$ & 0.833 & $85.967 \pm 3.769$ & $88.893 \pm 7.725 * * *$ & $0.570 \pm 1.277^{\mathrm{ns}}$ & -0.097 \\
\hline Chironomidae spp. (I) & 38 & $0.014 \pm 0.016^{\mathrm{ns}}$ & $1.383 \pm 0.290 * * *$ & 0.600 & $0.008 \pm 0.006^{\text {ns }}$ & $1.544 \pm 0.321 * * *$ & 0.533 & $79.307 \pm 2.643$ & $78.633 \pm 6.947 * * *$ & $0.070 \pm 0.688^{\mathrm{ns}}$ & -0.027 \\
\hline Phryganeidae spp. (I) & 10 & $0.001 \pm 0.001^{\mathrm{ns}}$ & $3.176 \pm 0.649 * * *$ & 0.746 & $0.001 \pm 0.001^{\mathrm{ns}}$ & $3.207 \pm 0.611 * * *$ & 0.789 & $91.851 \pm 2.137$ & $86.64 \pm 3.558 * * *$ & $0.382 \pm 0.185^{\mathrm{ns}}$ & 0.290 \\
\hline
\end{tabular}


415 Fig. 1. Maps of Scandinavia (small image) and the sampling area, marking the position of the 32

416 sampled bays with black circles.

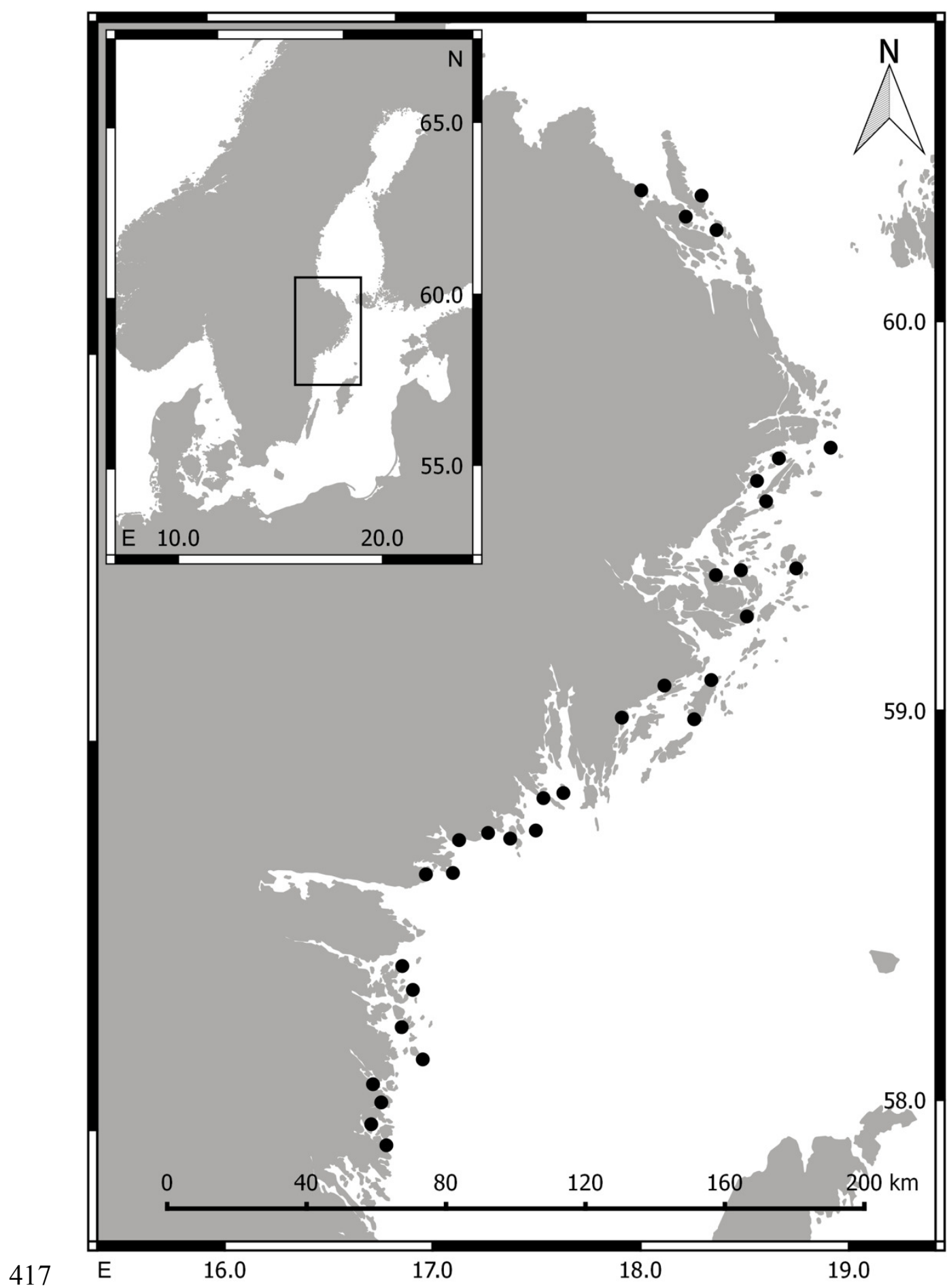

418 
420 Fig. 2. Best-fitting relationships between body size (length or height, see Methods) and a-d) dry 421 mass (mg. DM), e-h) ash-free dry mass (mg. AFDM) and i-l) AFDM/DM ratio (\% AFDM), for 14 422 taxa - five gastropods, three bivalves, three crustaceans and three insect larvae - sampled in coastal 423 areas of the central Baltic Sea. For model parameters and estimates of fit, see Table 1.

424

425

$\begin{aligned} & \text { Gastropoda } \\ &+\quad \text { Potamopyrgus antipodarum } \\ &-\bigotimes-\text { Hydrobia spp. } \\ &- \text { - Theodoxus fluviatilis } \\ &-\triangle-\text { Bithynia tentaculata } \\ &- \text { - Radix balthica }\end{aligned}$

a)

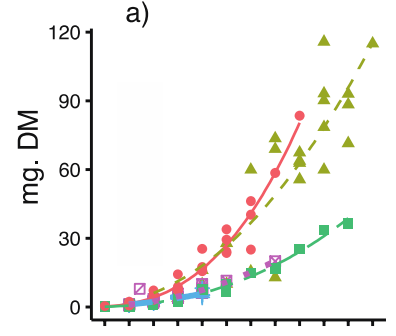

e)

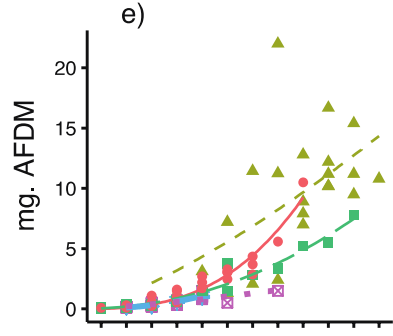

i)

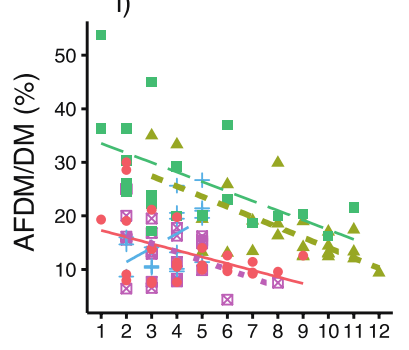

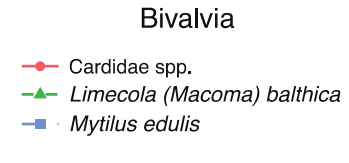

b)
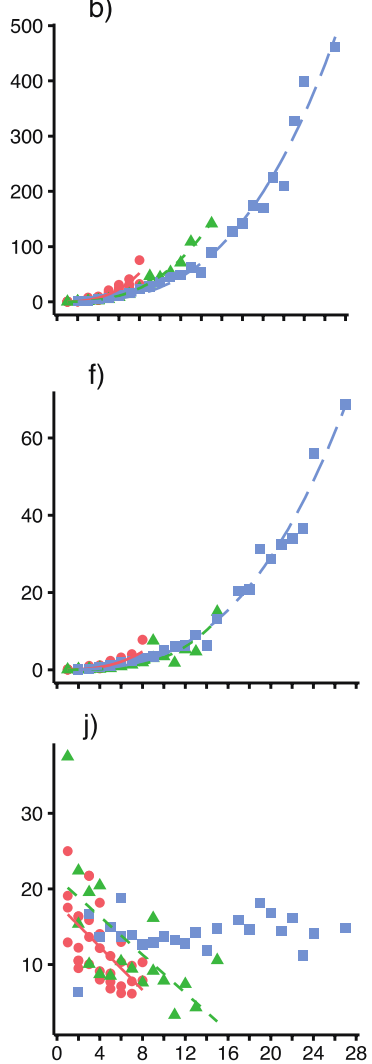

Crustacea

$\rightarrow$ Amphibalanus improvisus -4- Gammarus spp.

$\rightarrow$ Idothea spp.

c)

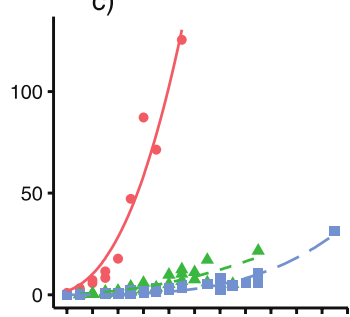

g)

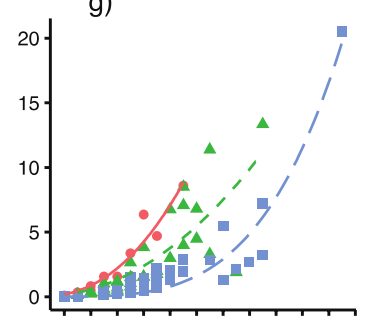

k)

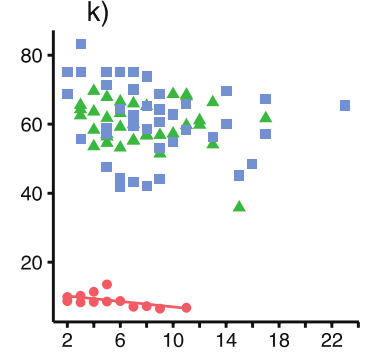

Length $(\mathrm{mm})$
Insecta (larvae)

$\rightarrow$ Phryganeidae spp.

-4- Agraylea spp.

$\rightarrow$ Chironomidae spp.

d)

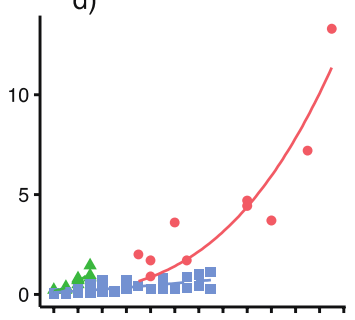

h)

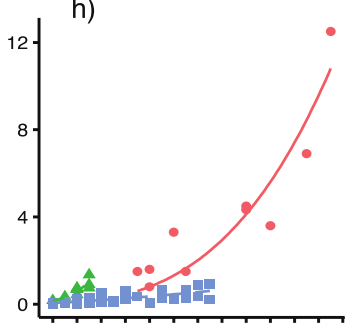

d)

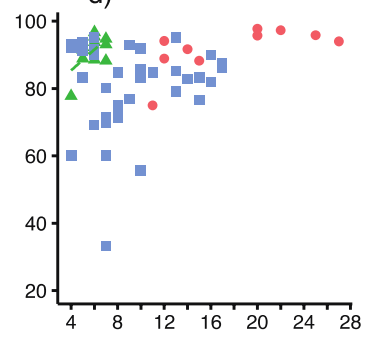

